\title{
A FORMAÇÃO URBANÍSTICA DO ENGENHEIRO JORGE DE MACEDO VIEIRA E O PLANO INICIAL DE MARINGÁ, PR
}

\author{
Fabíola Castelo de Souza Cordovil
}

\section{Resumo}

O engenheiro paulistano Jorge de Macedo Vieira formou-se pela Escola Politécnica, em 1917. A primeira exposição do seu acervo ocorreu na IV Bienal Internacional de Arquitetura de São Paulo, realizada no ano de 1999. A partir de então, pesquisadores têm se debruçado sobre o rico material deixado pelo profissional na busca de chaves para reconstituição da história e para a investigação da circulação de ideias do urbanismo no Brasil. Analisamos a atuação de Vieira tendo como referência o plano inicial de Maringá, de sua autoria. O plano, elaborado em meados da década de 1940, possui concepção fortemente permeada pela ideia de cidade-jardim de Ebenezer Howard, entre outras influências europeias e estadunidenses. Investigando a formação urbanística do autor, examinamos as suas relações profissionais e políticas, bem como as peças gráficas e as publicações que foram as suas referências.

\section{Palavras-chave}

Jorge de Macedo Vieira, plano inicial de Maringá, formação urbanística.

\begin{abstract}
The engineer Jorge Macedo Vieira was born in São Paulo and he graduated from the Escola Politécnica in 1917. The first exhibition of his collection occurred in the IV International Biennial of Architecture in São Paulo, held in 1999. Since then, researchers have been working on the rich material left by the professional in search of keys to reconstructing the history and research of the circulation of ideas of urbanism in Brazil. We analyze the performance of Vieira with reference to the initial plan of Maringa, of his own. The plan, drawn up in the mid-1940s, design has strongly permeated by the idea of the garden city of Ebenezer Howard, among other European and American influences. Investigating the formation of urban author, examine their business relations and policies, as well as graphic documents and publications that were his references.
\end{abstract}

\section{Keywords}

Jorge de Macedo Vieira, initial plan of Maringa, urban training. 


\title{
Introdução
}

O plano urbanístico de Maringá foi projetado pelo engenheiro Jorge de Macedo Vieira, contratado pela Companhia Melhoramentos Norte do Paraná - CMNP - em meados de 1940. No meio acadêmico, há abordagens diversas que enfocam características da cidade em sua localização de zona de povoamento recente e o seu desenho moderno. As pesquisas referem-se tanto à atuação profissional de Vieira quanto ao plano por ele elaborado.

O trabalho pioneiro sobre a atuação do engenheiro foi exposto na IV Bienal Internacional de Arquitetura de São Paulo, em 1999, coordenada pelo arquiteto e sociólogo Carlos Roberto Monteiro de Andrade. No "Catálogo da Exposição", salientam-se as reformas urbanísticas de São Paulo no início do século XX, distinguindo-se a formação profissional de Vieira, o seu estágio na Companhia City e a instalação de seu Escritório Técnico em áreas centrais paulistanas, nas quais se concentravam os escritórios mais influentes da época. Segundo os levantamentos apresentados, Jorge de Macedo Vieira projetou, em São Paulo, de 1918 a 1959, 13.195.912 $\mathrm{m}^{2}$ em loteamentos. Fora do estado, projetou em torno de $11.324 .448 \mathrm{~m}^{2}$, no período de 1925 a 1958. Além do parcelamento do solo, o engenheiro formulou planos para quatro cidades ou estâncias balneárias: Águas de São Pedro, em 1937, com 637.400m²; Maringá, em 1947, com 12.000.000m²; Pontal do Sul, em 1951, com 5.895.100m²; e Cianorte, em 1955, com 9.648.925 $\mathrm{m}^{2}$ (Andrade et alli, 1999). Sobre o projeto de Maringá, o "Catálogo da Exposição" contextualiza:

\begin{abstract}
Maringá, projetada em 1945 e fundada em 1947, teve seu traçado atentamente desenhado por Vieira, prevendo seus equipamentos urbanos, centro cívico e áreas destinadas à habitação, comércio e indústria. $O$ cuidado do seu traço se percebe na sinuosidade das ruas, que acompanham o relevo. Maringá, projetada para 200 mil habitantes, faz parte de um número expressivo de cidades criadas no período desenvolvimentista, dentro do processo de ocupação e urbanização do território brasileiro (Andrade et alli, 1999).
\end{abstract}

Um dos primeiros estudos sobre as ressonâncias do tipo cidade-jardim no traçado de Maringá foi realizado por Andrade (2000). O autor evidencia o pioneirismo do planejamento regional empreendido na região norte do Paraná e as influências britânicas, especificamente as influências do town and country planning. Andrade (2000) relaciona a atuação de Jorge de Macedo Vieira à formação urbanística que teve junto à Cia City, ainda estudante, e à possível convivência com Barry Parker, que projetou Letchworth e Hampstead. Conforme o autor, 
...é inegável que as claras filiações dos traçados urbanísticos do Eng. Jorge de Macedo Vieira às soluções tipo garden city, seja nos planos de cidades novas, ou no desenho urbano de loteamentos residenciais que projetou, e mesmo a qualidade urbanística de seus projetos, revelam influências diretas de Parker (Andrade, 2000).

Andrade e Steinke (2002), ao tratarem do urbanismo de Jorge de Macedo Vieira, destacam "sua interação com a cultura urbanística europeia e norteamericana" (Andrade e Steinke; 2002, p. 2). Os autores investigam aspectos da formação do engenheiro que influenciou sua atuação na área do urbanismo. Sobre a morfologia do traçado "tipo bairro-jardim" adotado pelo engenheiro em seus projetos, os autores explicitam as marcantes descaracterizações entre a concepção de Howard e os subúrbios-jardins realizados que influenciaram as concepções de Vieira e que se despojam do caráter reformista, mantendo apenas alguns elementos formais. Segundo os autores, "pode-se dizer que a disseminação a partir da pioneira experiência de cidade-jardim se deu através dos subúrbios, chegando até o Brasil na implantação dos primeiros empreendimentos da Cia. City em São Paulo, logo na primeira década do século XX" (Andrade e Steinke; 2002, p. 4).

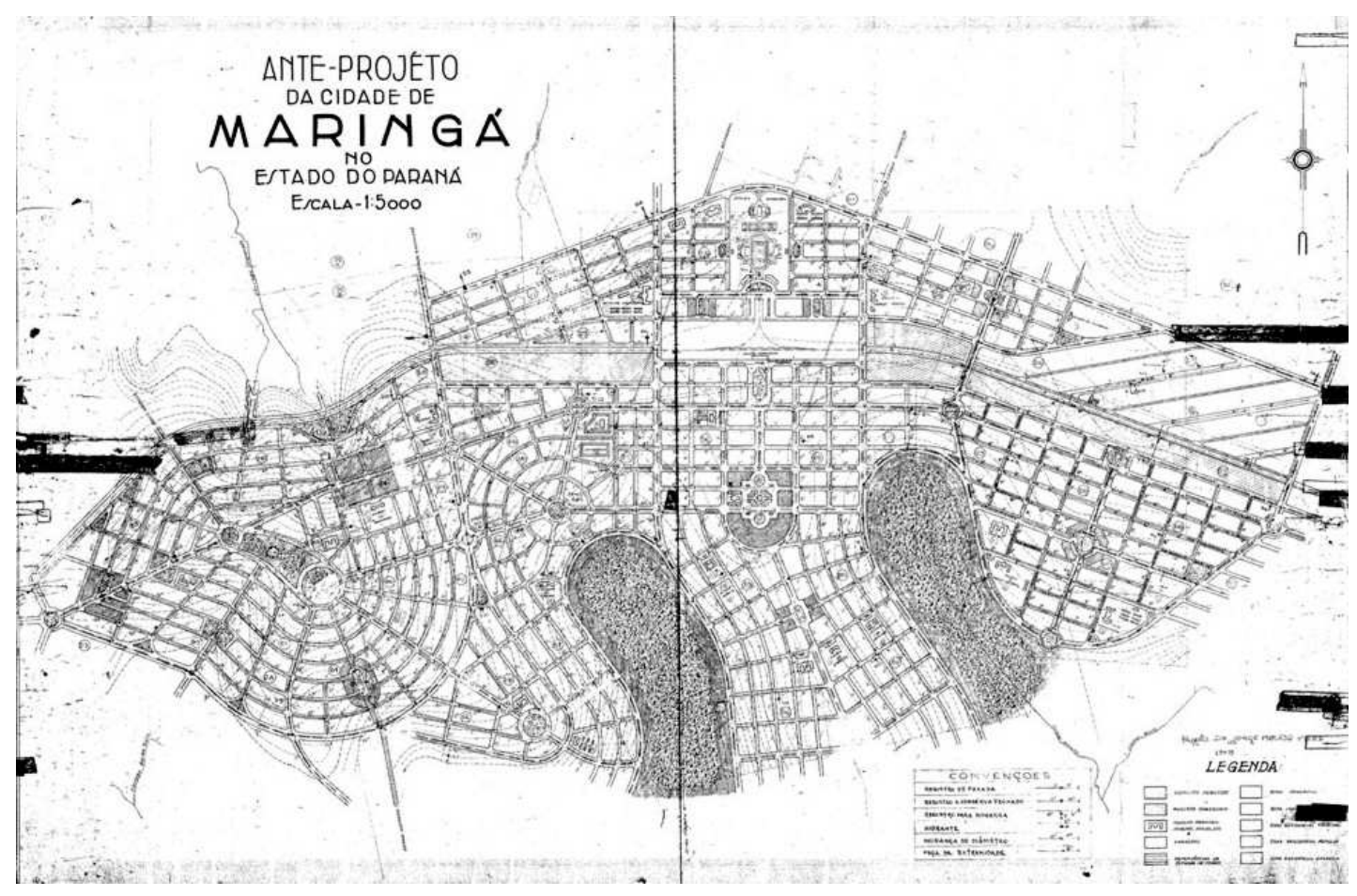

Figura 1. Ante-projeto para a cidade de Maringá, de autoria de Jorge de Macedo Vieira, elaborado em meados da década de 1940.

Fonte: Acervo do Museu da Bacia do Paraná. 
Em linhas gerais, o plano urbanístico de Maringá possui, como principais diretrizes de implantação, o eixo da ferrovia e o eixo central que o corta transversalmente. O eixo da ferrovia foi traçado no sentido leste-oeste, conforma-se na parte mais alta e plana do sítio, e, a partir dela, configuram-se as vias paralelas. 0 eixo central transversal à via férrea segue a mesma lógica do eixo da ferrovia, situando-se no espigão que divide os dois córregos, Moscados e Cleópatra. Estes têm a vegetação nativa preservada e abrigam dois parques (ver figura 1).

Abordamos a formação urbanística de Jorge de Macedo Vieira, analisando a sua formação urbanística e relacionando fatos e materiais que foram encontrados em seu acervo. Além disso, destacamos as pesquisas que já foram realizadas sobre a trajetória do engenheiro. No entanto, é necessário, antes de tudo, entender a influência política e econômica dos principais dirigentes da Companhia Melhoramentos Norte do Paraná, no intuito de estabelecer os vínculos profissionais e pessoais de Vieira que o levaram à formulação do plano de Maringá.

\section{Breve panorama da formação da Companhia Melhoramentos Norte do Paraná}

Partimos do momento em que a Companhia foi vendida a acionistas brasileiros, especificamente ao grupo liderado por Gastão Vidigal e Gastão de Mesquita Filho.

Na história da Companhia de Terras Norte do Paraná - CTNP, sucedida Companhia Melhoramentos Norte do Paraná - CMNP, a participação do engenheiro Gastão de Mesquita Filho é tida como das mais significativas. Formado em engenharia pela Escola Politécnica em 1919, participou do processo de aquisição das terras pela Parana Plantations Limited, entre 1924 e 1927, e foi diretor da CTNP/CMNP na década de 1940. A autora Wilma Kobayashi Mesquita (1995) comenta que, no início da década de 1920, Mesquita Filho foi responsável pela abertura e construção do trecho de $29 \mathrm{~km}$ da Companhia Ferroviária São Paulo-Paraná que ligaria Ourinhos a Cambará. Além disso, em janeiro de 1924, acompanhou a Missão Montagu ao Norte do Paraná. A missão inglesa, chefiada por Lord Lovat, representante da Sudan Plantation, estudava a possibilidade de investimentos no Brasil para o plantio de algodão.

$\mathrm{Na}$ ocasião, o engenheiro paulista "...expôs a ele [Lord Lovat] a idéia do aproveitamento da ferrovia São Paulo-Paraná como linha mestra do plano de colonização do Norte do Paraná com fertilíssimas terras" (Mesquita, 1995, p. 70).

Mesquita Filho foi considerado um dos mais sagazes empreendedores, conduzindo com habilidade a formação do grupo de acionistas para compra da Companhia e, posteriormente, consolidando a nova diretoria. Em obra comemorativa URBANA, V.5, no 7, out.2013 - Dossiê: Urbanistas e Urbanismo: a escrita da história... - CIEC/UNICAMP 
do cinquentenário da CMNP, lembrando que se trata de uma fonte institucional, registra-se que

...mais uma vez, o engenheiro Gastão de Mesquita Filho se aproxima da Companhia de Terras Norte do Paraná, depois de ter aberto os olhos de Lovat para as vantagens oferecidas pelas terras roxas existentes ao longo da margem esquerda do Paranapanema e de ter servido de intermediário entre o Major Barbosa Ferraz e os ingleses na venda, a estes, do trecho de 29 quilômetros da Companhia Ferroviária São Paulo-Paraná, que ele próprio havia construído, entre Ourinhos e Cambará (CMNP, 1977).

Segundo o seu depoimento, nessa mesma obra, Gastão de Mesquita Filho optou por trabalhar no interior devido à dificuldade da vida em São Paulo. Em sociedade com um irmão, apresentou à Companhia Ferroviária São Paulo-Paraná, que havia sido organizada pelo fazendeiro paulista Antonio Barbosa Ferraz Júnior em sociedade com outros fazendeiros, uma proposta para execução das obras da ferrovia. Em 1920, Ferraz Júnior e seus sócios conseguiram do governo estadual a exploração da estrada de ferro por 70 anos, com o projeto de ligar Ourinhos a Cambará a partir de uma conexão com a Sorocabana (Mesquita, 1995).

Em 1928, a Companhia Ferroviária São Paulo-Paraná foi comprada pelos ingleses e a obra foi assumida por uma empresa sediada em Londres, interrompendo os trabalhos iniciados por Mesquita Filho. Apesar da frustração relatada por este, podemos observar que o seu relacionamento profissional e pessoal the rendeu vantagens e favoreceu o trânsito que tinha em meios importantes, facilitando-lhe o contato com pessoas-chave para intermediar as negociações.

No seu depoimento, relata: "Quando os ingleses se interessaram em comprar a estrada de ferro - ao invés de financiá-la, como pretendiam os fazendeiros seus acionistas - eu fui a pessoa procurada para servir de intermediário, porque era amigo tanto de Lovat como do Major Barbosa Ferraz, as duas grandes figuras de um e de outro lado" (CMNP, 1977, p. 96). Mostrou ser um negociador diplomático e habilidoso, tirando vantagens financeiras das situações: "...Consegui conduzir a contento os entendimentos, fechou-se o negócio e eu recebi a minha comissão, que foi o primeiro dinheiro livre dos compromissos do lar que ganhei" (CMNP, 1977, p. 96).

A atuação de Mesquita Filho na Companhia revela a visão de conjunto e o caráter empreendedor dos engenheiros politécnicos na epopeia da construção da infraestrutura urbana e regional brasileira, a partir da criação da Escola Politécnica, em 1894. Reconhecemos a participação desse engenheiro como um dos primeiros técnicos que atuaram em Maringá, idealizando a sua criação.

URBANA, V.5, no 7, out.2013 - Dossiê: Urbanistas e Urbanismo: a escrita da história... - CIEC/UNICAMP 
O ensino adotado na criação da Escola Politécnica foi baseado no modelo alemão, que se caracterizava pelo ensino de ciências fundamentais e pela ênfase em ciência aplicada. Era uma reação à mentalidade livresca e ao bacharelismo vigente no ensino superior brasileiro da época e transformou a escola num dos principais agentes de propulsão do processo de modernização tecnológica da indústria paulista e nacional. A escola formava profissionais de larga visão, aptos a compreender os novos problemas que o processo de urbanização apresentava e a elaborar planos globais envolvendo saneamento, circulação e desenho urbano (Andrade et alli, 1999,p. 8).

O engenheiro foi o único brasileiro que manteve as ações da Companhia Ferroviária e integrou o seu conselho fiscal. Apesar de ficar afastado do Norte do Paraná entre 1929 e 1932, não deixou de manter contato com os ingleses e, especialmente, com o gerente da CTNP no Brasil, Arthur Thomas. Em 1936, foi convidado para organizar e explorar, juntamente com Rolando Davids, a Empresa Elétrica de Londrina, justamente no ano em que a estrada de ferro chegou àquela cidade. Segundo o seu depoimento, "...Dessa forma, continuava muito bom o meu relacionamento com a Companhia, mas nada me faria supor que um dia ela viesse a ser vendida a mim e a outros brasileiros, entre os quais eu faço questão de salientar o nome do meu particular amigo Gastão Vidigal" (CMNP, 1977, p. 96).

É significativa a amizade entre Mesquita Filho e Gastão Vidigal, que era, na época, eminente personagem da cena política e econômica brasileira.

Entre 1935 e 1946, Gastão Vidigal foi deputado federal por São Paulo. Em 1946, foi ministro de Estado da Fazenda do governo Gaspar Dutra. Além disso, foi "fundador do Banco Mercantil de São Paulo e um dos maiores financistas do país" (CMNP, 1977, p. 97).

O historiador José Henrique Rollo Gonçalves (1995) destaca o estreito relacionamento entre os dirigentes da CMNP e as elites políticas do Brasil dos anos 1930 e 1940. Assinala ainda que Gastão Vidigal "foi ministro quando ainda estavam sendo definidas as orientações estratégicas que o grupo de empresários paulistas, novos proprietários da CTNP, a partir de 1944, daria à firma". (Gonçalves, 1995, p. 52).

A sociedade entre Gastão de Mesquita Filho e Gastão Vidigal deu-se por ocasião do anúncio da venda da Companhia de Terras Norte do Paraná pelos ingleses, os quais, em decorrência da II Guerra Mundial, foram compulsoriamente forçados a devolver à Inglaterra os recursos ingleses investidos no exterior.

Além disso, com as mudanças políticas ocorridas no Brasil a partir de 1937, o governo federal apropriou-se das estradas de ferro, a exportação de capitais passou a URBANA, V.5, no 7, out.2013 - Dossiê: Urbanistas e Urbanismo: a escrita da história... - CIEC/UNICAMP 
ser severamente controlada e os impostos sobre os ganhos estrangeiros tornaram-se proibitivos. Em vista disso, os acionistas britânicos tinham dificuldades crescentes para receber os lucros dos investimentos feitos no Brasil (Monbeig, 1984, p. 239240).

A CTNP foi vendida ao grupo liderado por Gastão de Mesquita Filho. Seu interesse é descrito no livro comemorativo do cinquentenário da CMNP como um fato casual, quase uma coincidência, enfatizando-se a "naturalidade" com que os acontecimentos se desencadearam.

Um belo dia, em 1942, Gastão de Mesquita Filho visitava o Escritório Levy, em São Paulo, quando depara com uma das relações de companhias inglesas oferecidas à venda no Exterior, entre as quais figurava a Companhia de Terras Norte do Paraná. O engenheiro paulista imediatamente percebeu a magnífica oportunidade que se lhe oferecia, tanto assim que embarcou imediatamente para o Rio de Janeiro em busca do conselho e apoio financeiro do seu velho amigo Gastão Vidigal, que na ocasião ocupava o cargo de Diretor da Cechim, atual Cacex. (CMNP, 1977, p. 97).

Apesar da descrição tendenciosa que a CMNP faz sobre o rumo dos acontecimentos que levaram à aquisição da Companhia, possivelmente Gastão de Mesquita Filho, justamente por circular em rodas importantes de informações, aguardava a oportunidade com atenção.

O Escritório Levy, mencionado no depoimento de Mesquita Filho, era de composição familiar e uma corretora que oferecia uma gama de serviços, além de publicar, em 1929, o Boletim Comercial Levy, e em 1931, a Revista Financeira Levy, explorando o mercado de informações de câmbio, títulos e movimento bancário e ações. Em 1934, publicou a Gazeta Mercantil Industrial e Financeira, que deu origem ao jornal atual (Lachini, 2000). O fato de Mesquita Filho "visitar" o Escritório Levy, em 1942, evidencia sua característica de negociante bem-informado e que, provavelmente, já esperava a "magnífica oportunidade".

As negociações para aquisição da CTNP foram pactuadas por pessoas influentes da elite nacional. Políticos, empresários, advogados e engenheiros eram os personagens interessados na formação e desenvolvimento de novas infraestruturas urbanas e regionais no país. Esses empreendedores, combinados com a política nacional-desenvolvimentista, certamente acreditavam nas vantagens financeiras dos seus investimentos. 
A estreita relação entre os dirigentes da Companhia e personagens influentes na política brasileira esteve presente em muitos momentos. Gonçalves (1995) esclarece que

A intervenção dos dirigentes da CTNP na tentativa de conduzir uma identificação entre interesses paranaenses, interesses cafeeiros e interesses nacionais não foi, portanto, exclusiva. Antes, mais uma, dentre várias, empreendidas pelas classes dominantes regionais. O que não quer dizer, bem entendido, que não fossem pressões importantes, sobretudo considerando as intimidades entre aqueles empresários e pessoas influentes alocadas no aparelho do Estado, fenômeno que não ficou restrito aos anos 30, mas acompanhou boa parte da trajetória daquela empresa até recentemente. (Gonçalves, 1995, p. 52).

O autor destaca que importantes dirigentes da CTNP/CMNP participavam dos quadros das elites decisórias estaduais e nacionais. Entre eles, cita João de Oliveira Franco, que, em 24 de abril de 1931, foi o principal negociador paranaense do Convênio dos Estados Cafeeiros e dirigiu a Companhia Ferroviária Paraná-São Paulo, pertencente ao grupo inglês que controlava o Norte Novo do Paraná. Em 1938, Oliveira Franco foi secretário da Fazenda, Indústria e Comércio do estado do Paraná e, em 1939, Getúlio Vargas nomeou-o interventor interino (Gonçalves, 1995).

Arthur Bernardes Filho, pertencente ao grupo de acionistas que adquiriu a Companhia em 1944, era filho de Arthur Bernardes, presidente do Brasil de 1922 a 1926, e que convidou a missão inglesa chefiada por Lord Lovat para vir ao Brasil em fins de 1923, "...com o objetivo de estudar a reforma de nossa organização fiscal" (Mesquita, 1995, p. 69). Arthur Bernardes Filho seguiu a carreira política como o seu pai, sendo deputado federal por Minas Gerais de 1935 a 1937, em 1945 foi eleito deputado por Minas à Assembléia Nacional Constituinte, assumindo em 1946. Em 1947 abriu mão do mandato para tomar posse do senado de 1947 a 1959, foi vicegovernador de 1956 a 1961 e ministro da Indústria e Comércio do governo Jânio Quadros de 31 de janeiro a 25 de agosto de 1961 (DHBB - Dicionário HistóricoBiográfico Brasileiro, 2011).

Ao contrário do que se registra na edição comemorativa do cinquentenário da CMNP, ou seja, que somente Gastão Vidigal "podia ser considerado ligado à situação política vigente" (CMNP, 1977, p. 99), a compra da Companhia foi articulada por políticos atuantes. Porém os grupos Arthur Bernardes Filho e Soares Sampaio retiraram-se do empreendimento e o controle acionário ficou nas mãos de Gastão Vidigal e de Gastão de Mesquita Filho. 


\section{A elaboração do plano}

O plano de Maringá foi encomendado no momento em que a Companhia foi adquirida dos ingleses, entre 1943 e 1944. A possível proximidade entre Gastão de Mesquita Filho e Jorge de Macedo Vieira pode ser uma das chaves para o entendimento da escolha deste profissional para a elaboração do plano inicial. Ou, então, a indicação pode ter-se dado de forma indireta, a partir de Prestes Maia. Lembremos que a atuação de Gastão Vidigal como deputado federal coincidiu com o período em que Prestes Maia foi nomeado prefeito de São Paulo pela primeira vez, de 1938 a 1945.

Gastão de Mesquita Filho foi contemporâneo de Jorge de Macedo Vieira na Escola Politécnica. Formando-se dois anos depois de Vieira, certamente era conhecedor das transformações que se davam na capital paulista e da reconhecida competência deste profissional.

Outra chave importante seria a amizade entre Jorge de Macedo Vieira e Francisco Prestes Maia. Tal informação foi dada pela sobrinha-neta do engenheiro, em entrevista ao coordenador da exposição sobre o trabalho dele, na IV Bienal de São Paulo, em 1999. Além de amigos, Vieira e Prestes Maia formaram-se em engenharia na Escola Politécnica no ano de 1917.

A proximidade entre Prestes Maia, prefeito de São Paulo entre 1938 e 1945, e Vieira é comprovada nos projetos realizados na cidade de Campinas. Segundo o texto do catálogo da exposição O Urbanismo do Engenheiro Jorge de Macedo Vieira, da IV Bienal Internacional de Arquitetura de São Paulo, realizada em 1999, Vieira foi chamado para projetar bairros em Campinas no momento em que Prestes Maia foi contratado para assumir o seu Plano de Melhoramentos. Vieira havia elaborado a primeira planta cadastral da cidade no final da década de 1920. Na década de 1940, certamente indicado por Prestes Maia, Vieira ampliou suas atividades naquela cidade, projetando três bairros: Nova Campinas, Chácara da Barra e Vila Iza. Os dois primeiros situavam-se nas margens do córrego Proença, que "...fazia parte do plano na forma de uma park-way que fazia parte da perimetral externa da cidade e que começou a ser implantada na década de 40" (Andrade et alli, 1999, p.21).

Pela proximidade de Vieira com o ex-prefeito de São Paulo, há especulações sobre o convite feito para que exercesse a vida política. O fato de ter declinado do convite revelaria a personalidade de Vieira, como se deduz da seguinte assertiva: "Pessoa culta, dotado de grande modéstia, ao ponto de recusar a Prefeitura Municipal de São Paulo, cargo para o qual foi convidado no início do governo Ademar de Barros 
[1947-1951 e 1963-1966], indicando seu colega Prestes Maia" (São Paulo, 2009). Não encontramos, todavia, outras fontes que confirmassem essa afirmação.

Outra possibilidade aparece em decorrência do projeto para a cidade de Panorama, de 1946, elaborado por Prestes Maia. A cidade, que era terminal do tronco oeste da Companhia Paulista de Estradas de Ferro, localizava-se nas margens do Rio Paraná, no limite entre os estados de São Paulo e Mato Grosso do Sul. Além de ser ponta de trilhos, o sítio e a situação de Panorama assemelhavam-se à realidade da área onde se implantaria Maringá. Ambas as cidades foram construídas ex-novo e a partir de um projeto moderno, fazendo parte de um plano de colonização no qual a ferrovia teve papel preponderante. O projeto de Panorama pode ter sido uma referência para os acionistas da CTNP/CMNP, que, pela sua proximidade com os meios políticos, solicitaram o projeto da nova cidade norte-paranaense a Prestes Maia. Por impossibilidade de atender ao pedido, o ex-prefeito pode ter indicado o seu amigo Jorge de Macedo Vieira.

Embora a parceria entre Prestes Maia e Vieira tenha ocorrido em diversos trabalhos, não se encontram provas cabais de que o plano de Maringá tenha sido intermediado por Prestes Maia. O certo é que as indicações que levaram à escolha do autor do projeto da cidade se deram nas altas esferas das relações políticas da época, já que, como se viu, os empreendedores envolvidos circulavam em espaços importantes e influentes do cenário político nacional.

Junto com a elaboração do projeto de Maringá, Jorge de Macedo Vieira elaborou cálculos e plantas do trecho ferroviário entre Apucarana e Maringá, evidenciando-se sua participação no projeto no segundo e no terceiro trimestres de 1945 . Os registros foram encontrados no arquivo do engenheiro em consignação com o Departamento de Patrimônio Histórico, da Prefeitura Municipal de São Paulo - DPH/PMSP.

Em seu relato, a Companhia atribui ao engenheiro Cássio da Costa Vidigal uma importante participação na elaboração do plano inicial de Maringá. Segundo a Companhia, o projeto foi desenvolvido "...com base em anteprojeto de Cássio Vidigal e Gastão de Mesquita Filho" (CMNP, 1977, p. 137). Em sua biografia, podemos constatar que Cássio Vidigal nasceu no mesmo ano em que Vieira, ou seja, em 1894. Formou-se na Escola Politécnica e, em janeiro de 1918, assumiu a função de engenheiro da Secretaria da Agricultura de São Paulo. No mesmo ano ocupou a Diretoria de Obras da Prefeitura, encarregando-se do sistema rodoviário da capital. Foi membro do conselho diretor do Instituto de Engenharia em 1927 e 1928, exercendo o cargo de diretor-tesoureiro. Foi presidente da CMNP e publicou um estudo sobre o Norte do Paraná nos números 6 e 7 da revista Ateneu Paulista de URBANA, V.5, no 7, out.2013 - Dossiê: Urbanistas e Urbanismo: a escrita da história... - CIEC/UNICAMP 
História. Esse estudo encontra-se no anexo da edição comemorativa do cinquentenário da CMNP, sob o título Um estudo de Cássio Vidigal (CMNP, 1977, p. 6).

No seu depoimento, Jorge de Macedo Vieira explica que se baseou em uma planta topográfica fornecida por Cássio Vidigal. E, assim como a Companhia, Luz (1997) atribui a Vidigal o traçado das linhas mestras do projeto.

Com a demarcação definitiva da estação da estrada de ferro, $2 \mathrm{~km}$ a leste da primitiva posição, pelo Departamento Nacional de Estradas de Ferro, a Companhia de Terras Norte do Paraná mandou realizar os levantamentos e estudos da topografia local para o planejamento urbano. As linhas mestras para a construção da futura cidade foram estabelecidas pelo Dr. Cássio Vidigal, cabendo ao engenheiro Dr. Jorge de Macedo Vieira traçar o seu plano geral e definitivo. Com dados indispensáveis sobre a topografia, clima e a vegetação da região, que Ihe foram fornecidos pela Companhia, o referido urbanista planejou Maringá de acordo com a mais avançada concepção de cidade existente na época (LUZ, 1997).

A tentativa de identificar as relações de Jorge de Macedo Vieira com personalidades diversas leva-nos a concluir que o meio em que se formou apresentouIhe grandes oportunidades, proporcionando-Ihe relacionamentos importantes para contatos profissionais. Muitos de seus colegas e amigos estavam inseridos na política da época. Além disso, a própria localização do seu escritório técnico facilitava as aproximações com outros profissionais prestigiosos.

Seu escritório funcionou em alguns edifícios do Centro Velho paulistano, mas manteve-se, na maior parte desses 40 anos, no Palacete Palmares, à Rua Boa Vista $n^{\circ}$ 133. Nesse tradicional prédio eclético, que pertenceu à Condessa Álvares Penteado, estavam sediados muitos escritórios de profissionais liberais, refletindo uma característica de uso que predominou no centro de São Paulo até os anos 70 (Andrade, 1999 et alli).

\section{A formação urbanística de Jorge de Macedo Vieira}

Jorge de Macedo Vieira nasceu a 5 de agosto de 1894, na cidade de São Paulo. Além de assistir às transformações urbanas que se deram a partir do final do século XIX na capital paulista, participou ativamente da construção da metrópole que substituía paulatinamente a cidade provinciana. O engenheiro teve uma intensa atividade profissional entre as décadas de 1920 e 1950, projetando mais de duas dezenas de loteamentos que, assim como as cidades que planejou, incorporavam soluções inovadoras, tendo como referência as propostas que se realizavam no exterior. Quando menino, Vieira viveu em uma área central de São Paulo, na Rua do Carmo, e costumava subir ao terraço do sobrado onde morava para ver o panorama URBANA, V.5, no 7, out.2013 - Dossiê: Urbanistas e Urbanismo: a escrita da história... - CIEC/UNICAMP 
da cidade. No seu depoimento, ele diz que "... tinha o costume de ir nesse terraço ver a hora na Estação da Luz, pra poder dizer à minha mãe pra ela acertar o relógio" (Vieira, 1971). Foi avistando a Estação da Luz, inaugurada em 1901, e a cidade colonial que se modernizava, que Vieira alimentou o sonho de ser engenheiro. Dizia à sua mãe: "...um dia eu hei de ser engenheiro de ponts et chaussées. Ela perguntou: 'o que é isso?' 'Isso quer dizer de pontes e calçadas'. Fui engenheiro, mas fui engenheiro civil" (Vieira, 1971).

Segundo Maria Cristina da Silva Leme (1999), os melhoramentos davam-se em partes das cidades, especialmente em áreas centrais, e as reformas eram comandadas por profissionais formados em cursos de engenharia das Escolas Militares na Bahia, em Pernambuco e no Rio de Janeiro, ou na Escola Central do Rio de Janeiro. Os engenheiros "...ocupavam cargos públicos nas estruturas administrativas que estavam em formação nas prefeituras das principais cidades e no governo do estado" (Leme, 1999, p. 22). Com a proclamação da República, em 1889, e o consequente enfraquecimento das estruturas provinciais, o poder municipal assumira as suas atribuições. Em 1892 criou-se uma intendência de obras municipais que constituiu, em 1896, uma Comissão de Melhoramentos da Cidade (Leme, 1999).

Vieira viveu o momento em que a cidade colonial transformava-se na "capital do café", na qual os parâmetros de modernidade orientavam-se pela cultura europeia da época. O primeiro quartel do século $X X$ foi particularmente determinante para a mudança das estruturas físicas da cidade de São Paulo, com vistas à formação da metrópole. Nesse período a atuação da administração municipal foi marcante nas figuras pessoais dos seus prefeitos (Andrade et alli, 1999, p.7). A salubridade física e moral era a questão perseguida pelas grandes reformas sanitaristas que se concentravam nas áreas centrais. Cândido Malta Campos Filho (2004) comenta que,

Sob a égide do sanitarismo, expulsaram-se usos e moradores "indesejáveis" para a requalificação do centro urbano (...) Julgando resolver o problema da moradia, delegando ao rentismo privado, com regulações sanitárias mínimas, as políticas públicas de intervenção puderam se concentrar nos bairros da elite e no centro terciário (...) O centro e os bairros nobres davam costas à aglomeração industrial e operária que crescia ao longo do cinturão ferroviário nas várzeas do Tietê e do Tamanduateí... (Campos Filho, 2004).

Nas reformulações urbanas, os engenheiros tiveram papel preponderante. Além da construção da cidade, Leme (1999) explica que eles participaram da criação e do primeiro corpo docente das Escolas Politécnicas, em São Paulo e no Rio de Janeiro. Os principais campos de trabalho eram a construção de ferrovias e obras de 
infraestrutura das cidades, como saneamento, abertura e regularização do sistema viário. Conforme o historiador Cláudio Hiro Arasawa (2008, p. 30),

...a cidade de São Paulo (...) parecia misturar as virtudes de cidade pequena que era ainda, de fato provinciana, com aquelas que a faziam um foco irradiador de notável força de atração, materializada nos trilhos de ferro que para lá convergiam, no impulso econômico que dinamizava comércio, indústria e demografia, determinando a montagem das estruturas técnicas e científicas lá implantadas em curto espaço de tempo, que iam das redes de serviços de utilidade pública até as repartições administrativas e técnicas estatais, passando pelos institutos de ensino e/ou pesquisa montados de 1886 a 1925 (Arasawa, 2008).

Obras marcantes eram realizadas para conformar as estruturas físicas ao dinamismo econômico que convergia para o centro urbano. A reformulação do Vale do Anhangabaú foi uma das obras mais significativas da área central da capital paulista na época. Em 1911, quando Vieira tinha 17 anos, ou seja, um ano antes de entrar para Escola Politécnica, a proposta de Bouvard para o Vale do Anhangabaú contemporizou as polêmicas em torno da sua remodelação. "Em 1907, o vereador Augusto C. da Silva Telles publica seu opúsculo Melhoramentos de São Paulo, propondo transformar o fundo do vale do Anhangabaú em uma avenida central" (Andrade et alli, 1999, p. 4). A inspiração foi certamente a abertura da Avenida Central de Passos para o Rio de Janeiro, a partir de 1903.

A criação do Parque do Anhangabaú e a construção controlada de edificações na área foram possíveis graças ao acordo realizado entre a Prefeitura e o proprietário, conde Prates. "Sendo difícil impor normas reguladoras no ambiente liberal da República Velha, o acordo de cavalheiros obtido no Anhangabaú garantia um quadro representativo para a capital agroexportadora sem questionar o liberalismo dominante" (Campos Filho, 2004, p. 78).

Jorge de Macedo Vieira testemunharia, também, a verticalização do centro, que, com o Código de Obras de 1920, permitiu edifícios como o Sampaio Moreira, de 1924, e o gabarito de 20 andares do Martinelli, de 1930 (Campos Filho, 2004).

Na construção da cidade metropolitana, além das reformas empreendidas pelo poder público, outros agentes contribuíram, como "...as companhias de energia, ferrovias, empresas de melhoramentos urbanos e imobiliárias (...), e também proprietários de grandes glebas no Município (...) associados entre si e com vínculos estreitos com a Prefeitura e a Câmara Municipal" (Andrade et alli, 1999, p. 7). Entre esses agentes, Andrade (1999) destaca quatro: a S. Paulo Tramway Light and Power Co. Ltd.; a City of San Paulo Improvements and Freehold Land Company Limited; a URBANA, V.5, no 7, out.2013 - Dossiê: Urbanistas e Urbanismo: a escrita da história... - CIEC/UNICAMP 
Comissão Geográfica e Geológica, voltada a projetos de saneamento e retificação dos rios; e a Escola Politécnica.

Desses quatro agentes, que, além do poder público, desempenharam importantes atividades na construção da cidade de São Paulo, Jorge de Macedo Vieira participou de dois: estudou na Escola Politécnica de 1912 a 1917, foi estagiário da Companhia City no último ano do curso e, logo que se formou, fez parte de seu corpo técnico como engenheiro por dois anos.

Vieira ingressou na Escola Politécnica num momento em que os engenheiros eram formados para resolver os problemas da cidade, principalmente daquelas que serviam de ponto de escoamento de matérias-primas vindas do interior do país para os portos que davam acesso aos mercados do exterior. Segundo Arasawa (2008), o primeiro diretor e fundador da Escola Politécnica, Antônio Francisco de Paula Souza, ao modelar a escola segundo princípios dos institutos superiores alemães,

...operava uma dupla demarcação de território: se por um lado a escola projetada recusava-se a se filiar à tradicional Escola Politécnica do Rio de Janeiro, estabelecendo uma distância em relação a ela, produzida em contraposição da tradição politécnica francesa, cultivada no Rio de Janeiro, à concepção alemã de sistema de ensino de engenharia; por outro, ao reivindicar para a nova escola um estatuto de novidade epistemológica (novos procedimentos de construção da verdade legítima), acabava também por atribuir-Ihe a tarefa de transmutar os valores sociais, acreditando-a portadora de uma nova escala de valores, baseada no trabalho, na ciência, racionalidade etc. (Arasawa, 2008).

Criaram-se as bases para a montagem de instituições de julgamento do mérito técnico, com a fundação da Escola de Engenharia do Mackenzie College (1894) e da Escola Politécnica de São Paulo (1893), bem como o Instituto de Engenharia de São Paulo (Arasawa, 2008). "A necessidade imperiosa de engenheiros habilitados se apresentou em vários ramos das atividades privadas. No âmbito público, logo se fez sentir não somente no plano viário e da produção, como diante de tantas fundações urbanas recentes, além das mais antigas" (Marx apud Arasawa, 2008, p. 7).

As escolas faziam referências a modelos curriculares prévios para atribuir credibilidade aos seus sistemas de ensino. Arasawa (2008, p.100) afirma que

...produzia-se uma interpolação da nova escola na história da engenharia, procurando atribuir-Ihe valor. Se é assim, a Escola Politécnica de São Paulo constitui sua identidade como uma crítica ao modelo academizante da Escola Politécnica do Rio de Janeiro, fazendo referência à atualidade das Tecnische Hochschulen frente à tradição poderosa, mas supostamente passadista, da École Polytechnique de Paris (Arasawa, 2008).

URBANA, V.5, no 7, out.2013 - Dossiê: Urbanistas e Urbanismo: a escrita da história... - CIEC/UNICAMP 
Além das Escolas, outra instituição que contribuiu para o julgamento do mérito técnico foi o Instituto de Engenharia, fundado no dia 15 de fevereiro de 1917, o qual publicou boletins e revistas que eram fonte de informação para técnicos de todo o Brasil (Carpinteiro, 1996). Sylvia Ficher (2005) considera que no primeiro estatuto do Instituto de Engenharia, um dos principais objetivos era "a regulamentação do exercício da profissão, por meio de leis, avisos ou instruções, no sentido de ser assegurado, tanto quanto possível, aos engenheiros diplomados pelas escolas reconhecidas oficialmente do país ou do estrangeiro, o exercício da profissão (...)" (D'Alessandro et alli apud Ficher, 2005, p. 178).

Arasawa (2008, p. 162) comenta que "as origens do urbanismo como prática e disciplina em São Paulo, nas primeiras décadas do século $X X$, parecem indistinguíveis na figura de Victor da Silva Freire". O autor destaca que Freire ocupou três instâncias fundamentais do campo da engenharia: chefiou e organizou a recém-fundada Diretoria de Obras Municipais, cargo que ocupou por 26 anos; lecionou a cadeira de "Tecnologia Civil Mecânica" do curso de engenheiros civis da Politécnica de SP; e foi sócio fundador do Instituto de Engenharia de São Paulo. Além disso, fez parte, em 1939, do Conselho Técnico de Economia e Finanças do Estado de São Paulo, no governo Adhemar de Barros, e do grupo diretor da Light and Power, na década de 1940. Formar-se-ia um "circuito de validação social dos pontos de vista dos técnicos" (Arasawa, 2008, p. 163).

No circuito composto por essas três instituições de credibilidade técnica - a repartição pública, a universidade e a associação de classe - circulavam importantes personagens que tinham estreitos contatos pessoais e profissionais com Jorge de Macedo Vieira e que, assim como ele, se especializaram em urbanismo, estabelecendo profícuas parcerias.

Dentre seus colegas que se dedicaram à construção de cidades, Prestes Maia foi o que mais se destacou. Com Mariano Wendel, que veio a lecionar na Politécnica, Vieira manteve sociedade durante os primeiros anos de sua carreira. Com João Góes Manso Sayão Filho manteve estreita amizade e parceria profissional ao longo de sua carreira. Trabalharam juntos em abertura de loteamentos, de estradas de ferro e de rodagem, com destaque para sua atuação no norte Paraná, junto à Companhia Melhoramentos Norte do Paraná. Nessa parceria Macedo Vieira se encarregava dos projetos de urbanização, enquanto Góes Sayão cuidava da execução dos mesmos. Foram ainda seus colegas de turma os engenheiros Geraldo Ferreira Sampaio e José de Toledo Moraes, que trabalharam junto aos escritórios do engenheiro Saturnino de Brito (Andrade, 1999, p. 8). 
Já destacamos a importância das relações pessoais e profissionais de Vieira, que o inseriam no circuito de indicações e contratações de serviços técnicos. As parcerias profissionais são frequentes nos trabalhos relacionados ao urbanismo. Conforme o próprio engenheiro declara, o fato de ter estagiado na Companhia City enquanto era estudante e de, depois, ter sido contratado como engenheiro por ela, foram determinantes para o enfoque que deu à sua atuação profissional. A formação em engenharia civil dava-Ihe condições para atuar em diversas especialidades, mas foi trabalhando na Companhia City que Vieira escolheu a sua.

O engenheiro civil tem uma faculdade de escolher depois a sua especialidade, o que não se dá para o eletricista. Ele já tem que ser eletricista. Já o engenheiro civil não, ele tem mais, um campo mais vasto. Por exemplo, eu tendi para, eu não sou urbanista, eu tendi para o urbanismo, devido ter, logo que saí da Escola Politécnica, ter sido engenheiro da Companhia City daqui de São Paulo, que se pode dizer que foi a pioneira no urbanismo no Brasil (...) Eu saí da escola em 17. No último ano da Escola Politécnica, no sexto ano, portanto, eu já era auxiliar da Companhia City. Depois de formado fiquei lá como engenheiro dois anos. E a City, como foi a pioneira do urbanismo em São Paulo, lá eu aprendi muita coisa e, principalmente, o gosto pela especialidade (Vieira, 1971).

"Pioneira do urbanismo em São Paulo", conforme vaticinou Vieira, a Companhia City, teve de fato um papel primordial na construção da capital paulista de 1917 a 1930. A empresa adquiriu $12.380 .098 \mathrm{~m}^{2}$ de área no perímetro urbano, correspondendo, em 1912, a mais de um terço da área total da cidade (Wolff, 2001). Projetando para a elite paulistana, a Companhia City fundou diversos loteamentos nas regiões oeste e sudoeste. "Nos bairros-jardins do Pacaembu, Jardim América e Alto da Lapa, a City adotou modernos conceitos urbanísticos (...) derivados do Garden City Movement inglês" (Campos Filho, 2004, p. 80). A forte influência do padrão de subúrbio-jardim que marcou os loteamentos da Companhia City deve-se à contratação de Raymond Unwin e Barry Parker para a realização do projeto do Jardim América. De acordo com Andrade et alli (1999, p.9),

Adquirindo cerca de um terço da área então urbanizada da capital paulista, a Cia. City contratará, para a realização do que depois veio a ser o Jardim América, o escritório de arquitetura de Raymond Unwin e Barry Parker, expoentes do movimento pela cidade-jardim na Inglaterra, trazendo para a metrópole emergente o loteamento residencial tipo bairro-jardim. Parker veio para São Paulo implantar os primeiros bairros-jardins da City, trabalhando junto ao escritório da Cia., entre fevereiro de 1917 e janeiro de 1919, quando projetou o Jardim América, Pacaembu, Anhangabahú, Alto da Lapa e Bela Aliança, cerca de uma dezena de casas, além de elaborar para a URBANA, V.5, no 7, out.2013 - Dossiê: Urbanistas e Urbanismo: a escrita da história... - CIEC/UNICAMP 
municipalidade o projeto paisagístico do Parque da Avenida, junto ao Trianon (Andrade et alli, 1999).

Longe das propostas feitas para a primeira cidade-jardim de Howard, em seu livro de 1898, - que deveria ser uma cidade autônoma, de gestão comunitária, com um cinturão agrícola que limitaria o crescimento e grandes áreas verdes no interior da cidade - os bairros projetados pela Companhia City aproximavam-se do padrão urbanístico realizado no subúrbio-jardim de Hampstead, projetado por Parker e Unwin. Vieira trabalhou na City no momento em que esta inaugurava esse padrão para bairros residenciais na cidade de São Paulo. Sylvia Wolff (2001, p. 84) destaca as características dos novos loteamentos da Companhia:

O que distingue ainda hoje um bairro criado pela Cia. City são suas características de setor estritamente residencial, com casas para apenas uma família, com jardins em toda a volta, com alta densidade de vegetação não apenas nos jardins privados, mas também nas ruas públicas. Nessas vias a fiação elétrica é subterrânea e há densa arborização. Até recentemente não havia muros altos na frente das residências, apenas sebes vivas baixas atrás da quais transparecia a arquitetura das casas afastadas da rua. $O$ desenho das ruas, quase sem precedentes na São Paulo dos anos de 1910, desprezava o traçado regular de ruas em tabuleiro de xadrez, riscando eixos curvos e sinuosos e adaptava-se a curvas de nível dos terrenos mais irregulares como os do Pacaembu e da Lapa, vinculando-se aos esquemas dos subúrbios ajardinados e das cidades-jardins britânicas (Wolff, 2001).

Podemos afirmar que o aspecto formal dos bairros projetados pela City certamente influenciou a formação de Jorge de Macedo Vieira. Nas obras urbanísticas realizadas ao longo de sua carreira, observamos características correspondentes aos bairros projetados pela Companhia City. Ao sair da City, o engenheiro montou o escritório Vieira \& Wendell, no início da década de 1920, juntamente com um seu colega da Escola Politécnica, Mariano de Oliveira Wendell. A sociedade desfez-se em 1923 e, a partir daí, o escritório passiu a chamar-se Escritório Técnico Jorge de Macedo Vieira (Andrade et alli, 1999).

No acervo de Jorge de Macedo Vieira, em consignação junto ao DPH/PMSP, há quase uma centena de livros que faziam parte de sua biblioteca particular. A diversidade de publicações em idiomas como português, alemão, francês e italiano relaciona-se principalmente a áreas da engenharia civil. Alguns livros são de formação básica, que seguiam o currículo da Escola Politécnica, como os de física, matemática, cálculo, resistência dos materiais etc. Há outros de construção civil e de materiais de construção, bem como os de hidráulica e saneamento, os de estradas de rodagem e URBANA, V.5, no 7, out.2013 - Dossiê: Urbanistas e Urbanismo: a escrita da história... - CIEC/UNICAMP 
os de estradas de ferro, além, é claro, de urbanismo. Em menor quantidade, existem exemplares de assuntos não relacionados à engenharia, como os de ilustrações, os dicionários e até de xadrez. Além dos livros, há boletins e revistas que eram referências dos profissionais no período em que o engenheiro atuou. Do Instituto de Engenharia há o primeiro Boletim com a conferência inaugural "A orientação do engenheiro nacional", de 4 de agosto de 1917, de autoria de Victor da Silva Freire.

Até 1920, parece que Vieira manteve certa regularidade na aquisição dos boletins do Instituto. Porém na lista dos sócios do Instituto publicada entre 1917 e 1920 não consta o seu nome como afiliado. Entre os artigos de profissionais que Vieira colecionava, inseridos no Boletim, há o artigo de Saturnino de Brito "Notas sobre o traçado das ruas", publicado em agosto de 1920. Após esse período, verificamos que somente em 1955 as publicações do Instituto de Engenharia foram conservadas ou adquiridas pelo engenheiro. Constam no seu acervo exemplares da Revista do Instituto de Engenharia, de 1955 a 1968.

Além das publicações do Instituto, há diversos volumes de revistas, como a Arquitetura e Urbanismo, de 1936 a 1940. A edição de março e abril de 1937 publicou o texto "Goiânia - a nova capital de Goiás", de A. Correa Lima. A edição de julho e agosto de 1938 trouxe o artigo "O urbanismo na Inglaterra", de Patrick Abercombrie. Em março e abril de 1940, a revista publicou o resumo dos quatro Congressos PanAmericanos de Arquitetura realizados de 1920 a 1930. Além disso, no ano de 1940, há números com artigos de Luis Dodsworth Martins e de Lincoln Continentino. No acervo, existem volumes de outras revistas como a Revista de Engenharia Mackenzie e a carioca Revista do Clube de Engenharia.

Dos livros de sua biblioteca, destacamos os dois primeiros volumes de City Planning Housing, de Werner Hegemann, publicados entre 1936 e 1938. O primeiro volume tratava de "Historical and Sociological" e o segundo de "Political economy and civic art". De Henrique Dumont Villares, Vieira possuía Urbanismo e indústria em São Paulo, publicado em 1946. Nesse livro, segundo Andrade et alli (1999), provavelmente estava a referência de Vieira da cidade funcional, diversa daquela proposta por Le Corbusier. Deste arquiteto, no entanto, não se encontrou bibliografia no acervo de Vieira, a não ser no Où en est L'urbanisme - en France et a L'étranger, publicação decorrente do Congresso Internacional de Arquitetos, realizada em Strasbourg, em 1923, que contou com textos de Agache e Henri Prost, entre outros. Destacamos que Howard foi um dos vice-presidentes da diretoria do congresso.

Outra referência presente na biblioteca de Vieira é o livro de Louis van der Swaelmen Préliminaires d'art civique, publicado na Bélgica por volta de 1916, além do URBANA, V.5, no 7, out.2013 - Dossiê: Urbanistas e Urbanismo: a escrita da história... - CIEC/UNICAMP 
L'art de bâtir les villes, de Camillo Sitte, traduzido por Camille Martin em 1918. O livro do inglês Felix Clay Modern school buildings, elementary and secondary, de 1906, também fazia parte da biblioteca do engenheiro. Outros livros como o de Nelson Lewis The planning of the modern city, publicado em Nova Iorque em 1916, e o de Eurico Sodré A desapropriação por necessidade ou utilidade pública, de 1928, mostram que Vieira tinha conhecimento das ideias e propostas que se formulavam no Brasil e no exterior.

Com tais referências teóricas, Macedo Vieira articulará tanto uma concepção racional e funcionalista em relação à cidade, quanto um ponto de vista culturalista, que privilegia a paisagem a ser configurada e o panorama a ser descortinado. Associando traçados conforme o tipo cidade-jardim com princípios do urbanismo sanitarista de Saturnino de Brito, Macedo Vieira chega a soluções bastante originais, criando bairros-jardins e cidades-jardins agradáveis e com preocupações ambientais, preservando grandes áreas verdes e valorizando os cursos d'água e outros elementos da paisagem. Cria assim um urbanismo que é moderno, mas distinto daquele que deu origem a Brasília (Andrade et alli, 1999, p. 34).

Apesar de não se ter conhecimento de textos publicados de autoria de Vieira, no memorial do projeto para Pontal do Sul fica evidente que as concepções dos seus projetos traziam intrínseco o estudo de referências teóricas de "urbanistas de renome", tanto nacionais quanto estrangeiros. O memorial do início da década de 1950, apresentado à Prefeitura de Paranaguá, tem o seguinte texto:

O anteprojeto, desenhado, que vai anexo a este, serve apenas para fixação de ideia e discriminação das peças essenciais ao empreendimento, feito com os parcos elementos topográficos de que dispomos.

O projeto definitivo, orientado por urbanistas de renome, será confeccionado ao minucioso levantamento altimétrico e planialtimétrico da região a ser beneficiada e trabalhada (Vieira, ca. 1956).

Em nossa análise, a orientação a que Vieira se refere seriam as concepções teóricas de que tinha conhecimento e cujas características ele imprimia aos seus projetos desde o início de sua carreira. Destacamos a importância que o engenheiro atribui aos levantamentos topográficos para a elaboração detalhada do projeto definitivo. Observamos que, mesmo sendo o sítio de Pontal do Sul uma área essencialmente plana, a preocupação com o relevo é uma constante nas suas formulações urbanísticas. Em seu depoimento, considera que "...o xadrez não se admite mais. É inadmissível. Não se pode construir". Porém faz uma ressalva adiante, 
esclarecendo que o terreno é que deve orientar o traçado: "Quando ele [o terreno] permite, como o caso de Maringá" (Vieira, 1971).

Entre os documentos existentes no seu acervo, há folhas digitadas à máquina de escrever que se referem ao memorial descritivo do plano urbanístico de Águas da Prata. Segundo Amanda Cristina Franco (2005), o projeto da estância balneária foi elaborado por João Florence de Ulhoa Cintra, em 1923, e adequava-se "às concepções estéticas e técnicas defendidas por Saturnino de Brito" (Franco, 2005, p. 133). Nesse memorial, encontramos a justificativa feita por Ulhoa Cintra para o traçado irregular citado no texto de Brito "Notes sur le tracé sanitaire de villes".

É hoje opinião corrente entre os "urbanistas" que o traçado geral duma cidade deve ser adaptado à topografia do terreno. Em se tratando, no nosso caso, duma superfície altibaixa, afigura-se-nos que o traçado regular será de todo inaplicável. Procuraremos, portanto, resolver o problema que se nos deparamos por meio dum "tracés irrégulieres et mixtilignes, pour les mettres $d$ 'accord avec la topographie et les besoins à satisfaire, quant à I'écoulement des eaux et à la circulation des véhicules par les ponts convenables; on doit aussi le bel effet du pittoresque naturel et prévoir I'embellissement ultérieur de la ville". Rodrigues de Brito - "Notes sur le Tracé Sanitaire des Villes" (Vieira, ca. 1923).

Não sabemos o motivo que levou Vieira a guardar parte do memorial de Águas da Prata entre o material do seu Escritório Técnico. Todavia, podemos afirmar que compactuava da "opinião corrente entre os urbanistas" em relação à importância do relevo na definição do traçado geral da cidade, produzindo uma composição de traçados irregulares que considerasse os canais de drenagem e a circulação de veículos, sem descuidar do belo efeito pitoresco natural nas cidades projetadas. A cidade de Maringá reflete muito das concepções teóricas que formavam as bases dos projetos urbanísticos de seu autor.

\section{Comentários finais}

Embora o seu acervo já tenha sido investigado por pesquisadores e exposto em 1999, o rico material de trabalho e de estudo de Jorge de Macedo Vieira merece análises contínuas, devido às possibilidades de reflexões e análises ainda não totalmente exploradas.

As relações pessoais e profissionais que levaram o engenheiro a projetar a cidade de Maringá revelam aspectos importantes de como se davam os vínculos e as motivações políticas na primeira metade do século $X X$ no país. A inserção no meio político e a proximidade dos agentes que comandavam a Companhia Melhoramentos URBANA, V.5, no 7, out.2013 - Dossiê: Urbanistas e Urbanismo: a escrita da história... - CIEC/UNICAMP 
Norte do Paraná certamente possibilitaram a Vieira que desenhasse os planos iniciais de duas cidades pólos estabelecidas pela empresa: Maringá e Cianorte.

Salientamos a circulação dos acionistas da Companhia nas esferas importantes do cenário político brasileiro, demonstrando que a escolha do autor do projeto deu-se por indicações e aproximações com pessoas influentes, conhecedoras das tendências políticas e econômicas e dos negócios promissores. O novo empreendimento imobiliário, vinculado a uma estrutura regional maior, pensada duas décadas antes, deveria ter características peculiares, antevendo o sucesso de vendas, e precisaria ser criado dentro dos parâmetros das principais propostas urbanísticas que circulavam na Europa e nos Estados Unidos.

O acervo de Vieira, em consignação com o DPH/PMSP, contempla grande diversidade de títulos, peças gráficas e publicações que fizeram parte das referências do engenheiro, revelando situações e fatos que possibilitam a investigação sobre como as idéias circulavam no meio em que se formou e desenvolveu seus inúmeros trabalhos. Debruçar-se sobre tal acervo, relacionando-o com o contexto político, econômico e social da época, constitui uma das chaves para a reconstituição da história do urbanismo no Brasil, além de fomentar a discussão sobre a circulação das ideias urbanísticas.

\section{Referências bibliográficas}

ANDRADE, Carlos R. M. e STEINKE, Rosana. Desenhando uma nova morfologia: o urbanismo do Eng. Jorge de Macedo Vieira. In: SEMINÁRIO DE HISTÓRIA DA CIDADE E DO URBANISMO, VII, 2002, Salvador. Anais SHCU 1990-2008. Recife: UFPE, 2008. 1 CD-ROM

ANDRADE, Carlos Roberto Monteiro et alli. O urbanismo do engenheiro Jorge de Macedo Vieira. Catálogo da Exposição. IV Bienal Internacional de Arquitetura de São Paulo, São Paulo, 1999.

ANDRADE, Carlos Roberto Monteiro. Ressonâncias do tipo cidade-jardim, no urbanismo de cidades novas no Brasil. In: SEMINÁRIO DE HISTÓRIA DA CIDADE E DO URBANISMO, VI, 2000, Natal. Anais SHCU 1990 -2008. Recife: UFPE, 2008. 1 CD-ROM.

ARASAWA, Cláudio Hiro. Engenharia e poder. Construtores da nova ordem em São Paulo (1890-1940). São Paulo: Alameda, 2008.

CARPINTEIRO, Marisa V. O urbanismo do Instituto de Engenharia: São Paulo, 1920-1940. In: RIBEIRO, L. C; PECHMAN, R. (org). Cidade, povo e nação. Rio de Janeiro: Civilização brasileira, 1996.

URBANA, V.5, no 7, out.2013 - Dossiê: Urbanistas e Urbanismo: a escrita da história... - CIEC/UNICAMP 
CAMPOS FILHO, Candido Malta. Trezentos anos em trinta: a remodelação de São Paulo sob a primeira república. In: CAMPOS, C. M; GAMA, L. H.; SACCHETTA, V. (org.). São Paulo, metrópole em trânsito: percursos urbanos e culturais. São Paulo: Senac, 2004, p. 72-81.

COMPANHIA MELHORAMENTOS NORTE DO PARANÁ - CMNP. Colonização e desenvolvimento do Norte do Paraná. Publicação Comemorativa do cinquentenário da CMNP. 2. ed. São Paulo: CMNP, 1977.

CORDOVIL, Fabíola C. de S. A aventura planejada: engenharia e urbanismo na construção de Maringá, Paraná, 1947 a 1982. 2010. 636f. Tese (Doutorado em Arquitetura e Urbanismo). Escola de Engenharia de São Carlos, Universidade de São Paulo, São Carlos, 2010.

DHBB - Dicionário Histórico-Biográfico Brasileiro. Disponível em: <http://cpdoc.fgv.br/acervo/dhbb/>. Acesso em: 12 jan. 2011.

FICHER, Sylvia. Os arquitetos da Poli: ensino e profissão em São Paulo. São Paulo: Fapesp; Edusp, 2005.

FRANCO, Amanda Cristina. Cidades de cura, cidades de ócio: a influência de concepções estrangeiras no urbanismo de três estâncias paulistas: Águas de Lindoia, Águas da Prata e Águas de São Pedro: 1920-1940. 2005. $220 f$. Dissertação (Mestrado em Arquitetura e Urbanismo) - Escola de Engenharia de São Carlos, Universidade de São Paulo, 2005.

GONÇALVES, José H. R. História regional \& ideologias: em torno de algumas corografias políticas do norte-paranaense - 1930/1980. 1995. $255 f$. Dissertação (Mestrado em História) - Programa de Pós-Graduação em História, Universidade Federal do Paraná, Curitiba, 1995.

LACHINI, Cláudio. Anábase - História da Gazeta Mercantil. São Paulo: Editora Lazuli, 2000.

LEME, Maria Cristina da Silva (coord). Urbanismo no Brasil - 1895 - 1965. São Paulo: Studio Nobel; FAUUSP; FUPAM, 1999.

LUZ, France. O fenômeno urbano em uma zona pioneira: Maringá. Maringá: Prefeitura Municipal, 1997.

MARX, Murillo. Prefácio. In: ARASAWA, Cláudio Hiro. Engenharia e poder: construtores da nova ordem em São Paulo (1890-1940). São Paulo: Alameda, 2008, p. 7-9.

MESQUITA, Vilma K. Colonização e economia. In: CIOFFI et al. Cianorte. Sua história contada pelos pioneiros. Cianorte: Prefeitura Municipal, 1995. 
MONBEIG, Pierre. Pioneiros e fazendeiros de São Paulo. São Paulo: Ed. Hucitec, 1984.

SÃO PAULO (Prefeitura). Secretaria Municipal de Cultura. Departamento do Patrimônio Histórico. História das ruas de São Paulo. Disponível em <http://www.dicionarioderuas.com.br>. Acesso em: 12 fev 2009.

VIEIRA, Jorge de Macedo. Acervo. Memorial do projeto de Águas de São Pedro, sem autoria. São Paulo. [ca. 1923]. Acervo do engenheiro em consignação junto ao Departamento de Patrimônio Histórico de São Paulo.

VIEIRA, Jorge de Macedo. Memorial da proposta de fundação da cidade balneária de Pontal do Sul. Apresentada à Prefeitura Municipal de Paranaguá. Manuscrito. São Paulo. [ca. 1956]. Acervo do engenheiro em consignação junto ao Departamento de Patrimônio Histórico de São Paulo.

VIEIRA, Jorge de Macedo. Jorge de Macedo Vieira: depoimento [23 out. 1971]. Entrevistadores: Equipe do Serviço de Recursos Áudio-Visuais da Secretaria da Educação e Cultura de Maringá. Maringá: Prefeitura do Município, 1971. 1 cassete sonoro.

WOLFF, Silvia Ferreira Santos. Jardim América: o primeiro bairro-jardim de São Paulo e sua arquitetura. São Paulo: Edusp, Fapesp, Imprensa oficial do Estado, 2001. 